Rapid Reviews COVID-19•

\title{
Reviews of "Delta variant and mRNA Covid-19 vaccines effectiveness: higher odds of vaccine infection breakthrough"
}

Timothy Farinholt ${ }^{1}$, Lindsay Keegan ${ }^{2}$

${ }^{1}$ Baylor College of Medicine, ${ }^{2}$ The University of Utah

Published on: Sep 27, 2021

License: Creative Commons Attribution 4.0 International License (CC-BY 4.0). 
To read the original manuscript, click the link above.

Summary of Reviews: This preprint claims that, compared to Alpha, Delta cases have higher odds of vaccine breakthrough infections and lower mean Ct values. Although reviewers agree on the timeliness of this paper, they had concerns with the statistical methods used to get to the conclusions.

\section{Reviewer 1 (Timothy Farinholt)}

\section{Reviewer 2 (Lindsay Keegan, Jay Love)}

$$
\begin{aligned}
& \text { RR:C19 Strength of Evidence Scale Key } \\
& \text { प्रमप = Misleading } \\
& \text { प्र००० = Not Informative } \\
& \text { प्रा पि = Potentially Informative }
\end{aligned}
$$

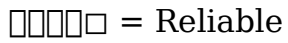

$$
\begin{aligned}
& \text { प्राप्र = Strong }
\end{aligned}
$$

To read the reviews, click the links below. 